severity of the spasms or in arresting the progress of the disease. From beginning to end the symptoms lasted only 27 hours.

\section{BARBADOES GENERAL HOSPITAL.}

A CASE OF REMOVAL OF 14 URIC ACID CALCULI WROM THE BLADDER BY THE AID OF AN EXTEMPORE RECTAL BAG.

(Under the care of Dr. T. SINChatr Browne.)

SURGEONS are always liable to be called upon to operate when unprovided with many of the appliances which are asually considered necessary and they are very ingenious in devising efficient substitutes, but we do not remember ever to have read of a more ingenious device than that recorded below by Mr. F. Deane. Petersen's bag is not essential in many cases of suprapubic cystotomy, but there are certainly cases when no safe degree of distension of the bladder suffices to raise the bladder so that it may be opened from above; in such instances the value of a rectal bag is often very great. For the notes of the case we are indebted to Mr. Frederick Deane, junior resident surgeon.

A coloured man, aged 52 years, was admitted into Ward 3 of the Barbadoes General Hospital on Jan. 19th, 1899 , with symptoms which were characteristic of vesical calculus. He was instructed to retain his urine on the night previously to examination and the bladder was sounded for calculus, and what was thought to be one very large calculus was detected lying behind the middle lobe of the prostate. The patient having consented to an operation he was prepared in the usual manner. On the 26th Dr. Sinclair Browne performed suprapubic cystotomy with the result that 14 uric acid calculi were removed from the bladder. The largest of the calculi when dried weighed 106 grains and the smallest 40 grains. The patient made an minterrupted recovery.

Remarks by Mr. Deane.-As vesical calculus is of exceedingly rare occurrence in Barbadoes our hospital does not possess a rectal bag, and although $I$ was aware that the rectal bag has at times been dispensed with by some surgeons, still I thought it advisable to have some such contrivance in readiness, so I obtained a piece of an old inner tube of a bicycle tyre nine inches long and sealed up one end with ordinary rubber cement, attaching to the other end a small piece of rubber tubing four inches long with an ordinary douche stop-cock attached to it, placing a piece of glass tube inside this rubber tubing so as to give it rigidity to receive the strapping for uniting the two. In this way was formed a sausage-shaped rectal bag, which acted splendidly, for the bladder on being distended with 12 ounces of warm boric lotion did not rise sufficiently above the superior border of the pubes to enable the operator to get freely at the portion of the bladder which is uncovered by the peritoneum; the extempore rectal bag was introduced into the rectum and distended with 12 ounces of warm boric lotion, with the result that the bladder was tilted apwards and forwards sufficiently to enable the operation to be performed without any risk of the peritoneum being wounded. I thought that this case might interest other surgeons practising in tropical climates where rubber in the shape of rectal bags and other instruments and appliances is very perishable and where the materials for making such a bag as the one above described can nearly always be easily procured.

State Children's Assoctation.-The second annual report of this association, the object of which is to obtain individual treatment for children under the guardianship of the State, says that the Bill introduced last session with the object of obtaining for the State further powers of control over neglected children which was unfortunately blocked has again been introduced and has received the sympathy of the Government. The tabulation of results is impossible, but it is noticeable that in the first 14 months of the existence of the association 13 recommendations of the Departmental Committee on Poor-law Schools were carried out, while the present report tells of 10 others which have been adopted or are in course of adoption. The report can be obtained, price $3 d$, at the office of the association, 58, old Broad-street, E.C., and also of Messrs. P. S. King and Son, 274, Great Smithstreet, S.W.

\section{adtedital Sorietitis.}

\section{ROYAL MEDICAL AND CHIRURGICAL SOCIETY.}

Clinical Examination of the Hamic Lencocytes.-Dysarthria. A MEETING of this society was held on April 25th, the President, Mr. BRYANT, being in the chair.

Dr. A. G. Phear read a paper on the Clinical Examination of the Hæmic Leucocytes. The purpose of this communication was to lay stress on the advantages of fluid preparations orer the cover-slip method more commonly in vogue in the study of the hrmic leucocytes. In the cover-slip method many of the leucocytes were inevitably flattened and distorted in the process of making and fixing the film; some were washed away during the staining of the film ; others were obscured by the largely preponderating number of red corpuscles. Distortion rendered accurate measurement and drawing of the cells impossible. In the fluid preparation the white cells were fixed and preserved as approximately spherical bodies; they were undistorted and camera lucida drawings and measurements could be relied on as accurate. The thickness of the unflattened cell was not a disadvantage; by gradually focussing from above downwards through the depth of the cell views could be obtained at different focal planes which were equivalent to a series of horizontal sections and a good idea was gained of the shape and disposition of the nucleus and other structures within the cell. In preparing the fluid film a solution of methylene blue ( 0.2 per cent.) in 40 per cent. alcohol was used for diluting the blood. The advantage of the alcoholic solution was that it laked the red corpuscles, so that the white cells alone remained conspicuous. A small quantity of the diluting solution was added to a drop of blood on a glass slide and the two were thoroughly mixed by directing a current of air through a pipette on to the surface of the fluid. The fluid was allowed to spread as a thin film under a cover-glass and the edges were then sealed with vaseline. The procedure took about three minutes. The preparation might be examined at leisure with an immersion lens and was available equally for a differential count of the leucocytes and for the study of individual cells. As to the normal leucocytes in fluid films the contour of the polymorphonuclear cells was, with rare exceptions, rounded. Their diameter varied from 9 to $10 \mu$; this was smaller than the apparent diameter of the flattened cells in dried preparations. With regard to the complex nucleus it could in almost every case be made out, by gradually changing the focus, that connecting strands passed from one lobe to another, the nucleus being, in fact, an undivided elongated body, in places deeply constricted, elsewhere bulged into rounded lobes. The lymphocytes and the large hyaline cells represented the extremes of a single group of cells, the members of which differed in no essential particular save in the amount of protoplasm around the nucleus; all grades between the extreme forms were readily found in normal blood. It was remarkable that the nuclear diameter was fairly constant in the cells of this group, varying only between 4.5 and $5.5 \mu$. In films prepared by the method advocated a group of ${ }_{k}^{z}$ cells could be differentiated (large oval cells) which found no place in commonly accepted classifications. The cells were the largest of the normal leucocytes and the only ones whose forms departed notably from the spherical. They might be as much as $14 \mu$ in length. Their contour was oval and the nucleus was large and irregular, usually reniform. The protoplasm became rapidly and uniformly stained an opaque blue colour with methylene blue. The coarsely granular or eosinophile cells (diameter from 9.5 to $10.5 \mu$ ) were at once recognised in the film prepared with methylene blue solution notwithstanding the absence of an acid dye; the large refractile granules were conspicuous and were tinged a greenish colour. The cells containing basophile granules (diameter about $8 \mu$ ) had a characteristic appearance. The protoplasm contained granules of medium size, many of which were aggregated in one or more deeply stained clumps near the surface of the cell. The non-gtanular part of the protoplasm was stained a peculiar mauve or purple colour. The nucleus consisted of a number of lobes usually massed at the 